\title{
Analysis of Ergonomics Risk Factors and Manual Material Handling Assessing Alternative Using Cost Benefit Methods
}

\author{
Eko Nurmianto $^{1}$ and Udisubakti Ciptomulyono ${ }^{1}$
}

\begin{abstract}
This research to analyze the factors that cause risks of low back pain (L5/S1) on Manual Material Handling activities at raw material warehouse and finished goods warehouse. Objective is to determine the factors that cause low back pain (L5/S1), analyze the proposed improvement work system alternative with benefit cost ratio (B/C). The importance of costbenefits analysis of ergonomics interventions has been emphasized (Tompa et al., 2009; Rivilis et al., 2008). Methodology by observing MMH working system, and distributing job discomfort survey. For the quantitative calculation used RWL, LI and Chaffin's Model. The model of analysis shows the factor effected to RWL and LI is variable V (vertical distance), D (distance movement), and $L$ (heavy of load). Examples of alternatives proposed : (1) addition of scissor of lift trolleys, (2) addition in amount of workers and (3) modifying of lifting method. Alternative whose the $B / C$ value $\geq 1$ are feasible economically to be used. Top management needs a cost-benefit analysis proving the positive outcomes. This economics evaluation showed that ergonomic intervention justifies the costs of the implementation, leading to positive outcomes.
\end{abstract}

Keywords - MMH, Ergonomics, RWL, Chaffin model, benefit cost ratio (B/C).

\section{INTRODUCTION}

$\mathrm{M}$ anual material handling $(\mathrm{MMH})$ is all the work of bearing the load (twisting, bending, reaching, lowering, pushing, pulling, carrying, and reverse) were carried out by workers in order to move the load. Reason for this is the use of MMH due to several advantages that can be gained is more flexible in motion the transfer of material at the work site of irregular / not neat and cheaper and easier to do for a light load. MMH activity in fact contain a high risk as a result of work overload is removed (over-exertion) as well as the methods used do not work properly. Research concentrated on building classification models that could effectively distinguish between high risk and low risk MMH tasks that contribute to LBDs (Zurada, 2012; Zurada, Karwowski, \& Marras, 2004).

The importance of costs-benefits analysis of ergonomics interventions has also been emphasized (Simpson, 1988; Hendrick,1996, 2003; Tompa et al., 2009; Rivilis et al., 2008), guidelines for cost-benefit evaluation have been proposed (Hendrick, 2003).

Nevertheless, few studies (Tompa et al., 2009) carried out such analysis (Rivilis et al., 2008) due to the variety of factors involved and the complexity to quantify these factors (Tompa et al., 2009). Simpson (1988) and Hendrick (1996, 2003) bring some examples of costbenefit evaluations in ergonomics and stress the reluctance of ergonomists in evaluating the "economics of ergonomics" and the importance of a "good" ergonomics intervention, i.e., one that considers all aspects related to the work or a macroergonomic intervention. The costs and benefits measurement is fundamental in demonstrating that these interventions are not a cost for the company but a means for obtaining better outcomes both for the workers and the company.

${ }^{1}$ Eko Nurmianto and Udisubakti Ciptomulyono are with Departement of Industrial Engineering, Faculty of Industrial Technology, Institut Teknologi Sepuluh Nopember, Surabaya, 60111, Indonesia. E-mail: nurmi@sby.centrin.net.id; udisubakti@ie.its.ac.id.

\section{MANUAl MATERial HANDLiNG}

\section{A. Principles of Manual Material Handling}

The appointment and removal of the burden of manually if not done properly will cause accidents in the industry (Ayoub \& Mital, 1989). Industrial accidents (industrial accident) are referred to as "over-exertion of lifting and carrying" the tissue damage caused by excess weight lifting. If the human body is lifting a load, then the entire body will experience some sort of stress. Muscle basically serves to uphold the human body and if this muscle fatigue given the additional burden it would soon be felt. If someone lifting weights then the body muscles will tighten and shrink the blood vessels, as a result the person will feel tired. If this continues, it will cause accidents that endanger the safety and health of workers. Tension that affects the body's muscles will be more severe if the received increasingly heavy burden and recurrent (repetitive) and the appointment is not true.

Principles of lifting the burden of manually:

a. Adjust the weight of the worker's ability to consider the frequency of removal (if it can be reduced).

b. Holding cultivated by all parts of the hand

c. Back and arms arranged in a straight position

d. If the load to be lifted from the floor should wear aids.

e. The position of the foot is made in such a way to withstand the load during lifting

f. Cultivated load as close as possible to the vertical line through the center of gravity of the body

g. Shorten the distance between the horizontal movements begin with the end in the removal of the load

h. Applicability of job rotation to work that requires manpower and adequate rest periods

i. Heavy object placed knee, so that the removal does not cause injury

Some of the factors that influence the material removal manually (Nurmianto, 2004: 149) are as follows:

a. Comparison between the weight that must be lifted by weight 
b. Horizontal distance of the load relative to the operator

c. Size (dimensions) load to be lifted, which has a large load center of mass (center of gravity) that is located far away from the body allowing workers have difficulty in lifting it .

d. Height of the load to be lifted and the distance moved by the load, where the removal of the load from the floor surface will be relatively more difficult than lifting weights from waist height

e. Load torque (twisting load) in the body of the operator during lifting activities.

f. Prediction of the weight of the load to be lifted, in anticipation of a heavier load than expected

g. Stability of the load is lifted

h. Easy to reach workers

i. Many obstacles that hinder or limitations posture is at a workplace

j. Working conditions, including lighting, temperature, noise, and others.

k. Frequency is the number of lift lifting activities

l. Lifting the right way (should not carry the burden of sudden).

m. Not coordinated working groups

n. She picked up a load in a period

While some of the parameters that must be considered are as follows:

a. Burden to be lifted.

b. Comparison between the load and its weight.

c. Horizontal distance from the load to the person.

d. The size of the load to be lifted.

In the process of lifting weights, lift restrictions can help to reduce fatigue for workers. Lift this restriction will reduce the inconvenience of work, especially for operators of heavy work such as lifting weights. To find out the grievances felt by the workers when interacting with objects in a qualitative work, in this study used a questionnaire called the discomfort survey job. The full form of discomfort job this survey can be seen in the following table (see appendix).

\section{B. NIOSH lifting equation to manually load}

National Institute of Occupational Safety and Health (NIOSH) has made an equation that can assist analysts in evaluating an employment / appointment and removal activity manual materials on the sagittal position by focusing on the aspects of safety and health for workers. $\mathrm{NIOSH}$ issued this equation (lifting equation) gives a theoretical value of the load lift is recommended for employment / activity called loading the Recommended Weight Limit (RWL). This equation does not include factors / conditions that were not foreseen (Occupational Hazards, 2004) , such as unexpected heavy load, slip or fall, and again this equation is not designed to assess the work includes removal using one hand (one-handed), lifting, kneeling or sitting position, lifting the restrictions workspace (workspace too narrow) or removal of an object that is more than 30 inches. In NIOSH gender is not taken into account/consideration (RWL applies equally to male and female workers).

Overview of this equation is to prevent and reduce the occurrence of injury especially lower spine (low back pain) for workers in performing activities manually lifting loads. NIOSH model is based on data biomechanical, physiological and psychophysical. Approach to biomechanics, physiological and psychophysical in determining RWL can provide a result that led to the recommendation that different from one another. For an overview of biomechanics its design criteria is the maximum compressive force with a limit value of $3.4 \mathrm{kN}(770 \mathrm{lb})$, while the psychophysical criteria for designing the review is the maximum weight that can be accepted by the value of the limit is acceptable by $75 \%$ of female workers and $99 \%$ of male workers.

NIOSH equation multipliers on comprised of six coefficients are used as a constant reduction of compensation expense based on the characteristics of the different lifting loads from a standard location lifting weights or optimal conditions. According to Chaffin (1991), as stated in the research Snook (1978), the conditions or factors identified as one or more of the epidemiological studies on appointment load manually. Epidemiological study is a study that takes into account the nature of the work, the workplace and other factors that provide a significant trend as the cause of the accident/injury. In 1991 the revised NIOSH equation by adding the two numbers in the multiplier method of evaluation. So that the new equation provide a procedure for evaluating job with longer timescales and higher frequencies with better results. All multipliers (coefficients) obtained from a number of iterations where the empirical coefficients that have been revised are used to estimate the load that may be transported. Loads obtained from the calculation is then compared with the empirical study of psychophysical. Formula of RWL equation in question is:

$\mathrm{RWL}=\mathrm{LC} \times \mathrm{HM} \times \mathrm{VM} \times \mathrm{DM} \times \mathrm{AM} \times \mathrm{FM} \times \mathrm{CM}$

Description:

1) LC (Lifting Constanta)

Constant load is determined based on the maximum allowable load to be lifted in the standard location under optimum conditions. The sense is the removal done on sagittal position with the appointment of frequencies that are not too often, clutch is good, and the location of the displacement is less than $25 \mathrm{~cm}$. The selection criteria are based on the constant burden of psychophysical and biomechanics. In the revised equation, the value of the constant load is reduced from $40 \mathrm{~kg}$ to $23 \mathrm{~kg}$. This reduction was due to the increase in the minimum horizontal distance of $15 \mathrm{~cm}$ to $25 \mathrm{~cm}$ in standard transport position.

\section{2) HM (Horizontal Multiplier)}

From the standpoint of biomechanics and psychophysical horizontal distance of the load that the spine will lead to the greater compression force on the vertebrae that great anyway, and can reduce the maximum load allowed to be appointed. Horizontal multiplier is calculated by the following equation:

$\mathrm{HM}=(25 / \mathrm{H})$

Where $\mathrm{H}=$ horizontal distance between the midpoint direction ankle on place of origin before the load is lifted in $\mathrm{cm}$ (Figure 1).

3) VM (Vertical Multiplier)

Multiplier vertical position, defined as the vertical position of the foundation place of origin before the load is lifted. From the standpoint of biomechanics will increase stress on the lumbar if the appointment is done 
by the load position perilously close to the floor. Study of the epidemiology indicates that the load is getting closer to the floor associated with the growing percentage of spinal cord injury due to lifting the burden of the bottom. Meanwhile, according to the view of physiology study states that the adoption load closer to the floor causing the increasing energy expenditure. According to Snook (1978), Ayoub et al (1989), Snook \& Ciriello, (1991), the maximum load that may be lifted (MAWL - Maximum Acceptable Weight of Load) by workers decreases with increasing vertical distance more than $75 \mathrm{~cm}$ from the floor. Appointment with the way in which the load is carried bent on the floor (base). For removal of floor level load (shoulder level) results from the vertical multiplier factor is as follows:

$\mathrm{VM}=(1-.0030 \mid \mathrm{V}-75)$

Where $\mathrm{V}=$ the vertical distance between the initial position of the load with the load on the current position will be appointed in cm (Figure 1).

4) DM (Distance Multiplier)

Results of psychophysical studies predict a decrease of $15 \%$ against MAWL if distance moving closer to the maximum (weight lifted from floor to shoulder) and will be increased in line with increased physiological needs lifting distance. Distance multiplier determined by the following equation:

$\mathrm{DM}=0.82+(4.5 / \mathrm{D})$

Where $\mathrm{D}=$ distance moving / lifting the vertical distance between the point of origin and destination (cm).

$\mathrm{D}$ is assumed between $25 \mathrm{~cm}$ to $(200-\mathrm{V}) \mathrm{cm}$. For vertical displacement distance of less than $25 \mathrm{~cm}$ used value $\mathrm{D}=2$.

5) AM (Asymmetric Multiplier)

Appointment of appointment of load asymmetry is not located in the sagittal plane or appointment in which the workpiece is placed at an angle to the sagittal plane and removal of asymmetry also supports a reduction in the MAWL. Asymmetry multiplier is calculated by the equation:

$\mathrm{AM}=1-(0.0032 \mathrm{~A})$

Where $\mathrm{A}$ is the asymmetry angle formed when material removal activity $\left(^{\circ}\right)$. Asymmetric angle is the angle that indicates the extent to which items / objects transferred from the worker's body to the point of destination.

6) FM (Frequency Multiplier)

This multiplier indicates how often the activity of lifting material / load carried. FM values are given in Table 1.

7) CM (Coupling Multiplier)

What is meant here is a combination of clutch work hand function workers with hand grip (handle). Psychophysical investigation results indicate that the decline in the value of the work of bearing load MAWL are not equipped to handle that well. CM value is determined based on the quality of the coupling that connects the arm to the goods / load being transported. Good clutch will be able to reduce grip force required to lift the load, while a bad clutch will require greater grip style so that it can reduce the ability to lift workers. CM values are given in the following table 2.

Determination of a good quality clutch (object / object) is influenced by the type of handle, shape of goods, so it can be expressed how difficult or easy the item can be removed manually.
Lifting Index (LI) stating the estimated value of the relative level of physical stress in an activity manual removal. LI magnitude is expressed as follows:

$L I=\frac{L}{R W L}$

L (load weight) states the burden is lifted. The greater the value of LI indicates the fewer the number of workers that can do the job safely survive in the certain stress level.

\section{Chaffin’s Static Sagital Plane Model}

Models and equations created by Chaffin (1991) provide estimates of the magnitude of compressive force on L5/S1 for an activity specific loading and unloading. This model can also predict the proportion of the population who will have the strength to body connection for transport activity. In this model system includes the connector between the hip joint and spine segment (L5/S1) and the influence of abdominal pressure (abdominal pressure) which serves to help the stability of the body of influences and styles available moment. Biomechanical model of the basic elements for lifting activities are illustrated in Figure 2. Biomechanics analysis according to Chaffin is as follows (Nurmianto, 2004:174):

a. Weight (weight) load of $\mathrm{W}$ and the upper body (upper body) $\mathrm{w}$ resulted in a great moment at the L5/S1 moment arm caused by $h$ and $b$.

b. This moment must be balanced by a very large muscle force (muscle force) Fm because it reacts with force moment arm E, thus causing the price of the magnitude of compressive force on L5/S1 (Fc).

c. Minimize price by lowering prices Fc done moment arm $h$ and $b$.

d. Involve the influence of the pressure inside the abdomen (intra-abdominal pressure) FA is likely to reduce the magnitude of $\mathrm{Fc}$.

As the example for the calculation is as follows:

a. Calculation of the value or moments at the hip

a. $\mathrm{M}_{\mathrm{H}}=\mathrm{b} \cdot \mathrm{w}+\mathrm{h} \cdot \mathrm{W}$

b. The pressure that occurs in the stomach (PA)

a. $\mathrm{P}_{\mathrm{A}}=10^{-4}\left[43-0,36\left(\theta_{\mathrm{H}}+\theta_{\mathrm{T}}\right)\right]\left[\mathrm{M}_{\mathrm{H}}\right]^{1,8}$

c. Assuming that the abdominal area is $465 \mathrm{~cm}^{2}$ diaphragm, the abdominal pressure becomes (after converting PA into $\mathrm{N} / \mathrm{cm}^{2}$ ) :

a. $\mathrm{F}_{\mathrm{A}}=\mathrm{P}_{\mathrm{A}} \times 465$

d. Muscle force $F_{m}$ (taking into account the value of the moment L5/S1)

a. $\mathrm{F}_{\mathrm{m}} \cdot \mathrm{E}=\mathrm{b} \cdot \mathrm{w}+\mathrm{h} \cdot \mathrm{W}-\mathrm{D} \cdot \mathrm{F}_{\mathrm{A}}$

b. $\mathrm{F}_{\mathrm{m}}=\frac{b w+h W-D \cdot F_{A}}{E}$

e. Compression force $F_{c}$ (obtained by summing all forces perpendicular to the L5/S1)

a. $\mathrm{F}_{\mathrm{c}}=(\mathrm{w}+\mathrm{W}) \sin \theta_{\mathrm{A}}-\mathrm{F}_{\mathrm{A}}+\mathrm{F}$

where :

$\mathrm{M}_{\mathrm{H}} \quad=$ moments at the hip (Nm).

b = L5/S1 horizontal distance to the center of mass of the body above the L5/S1 (cm). 
b' = Horizontal distance to the center of body mass hips above L5/S1 (cm).

$\mathrm{h}=\mathrm{L} 5 / \mathrm{S} 1$ horizontal distance to the center of mass of the load (cm).

h' $\quad=$ Horizontal distance of the center of mass of the load to the hips $(\mathrm{cm})$.

$\mathrm{P}_{\mathrm{A}} \quad=$ Abdominal pressure $(\mathrm{mmHg})$.

$\mathrm{F}_{\mathrm{A}} \quad=$ Abdominal pressure force generated $(\mathrm{N})$.

$\mathrm{F}_{\mathrm{m}} \quad=$ The force on the muscle spinal erector $(\mathrm{N})$.

$\mathrm{F}_{\mathrm{c}} \quad=$ Compression force on the L5/S1 (N).

$\mathrm{w} \quad=$ Weight of body segment above the L5/S1 (N).

$\mathrm{W} \quad=$ Weight of load $(\mathrm{N})$.

$\mathrm{E}=$ Distance of muscle spinal erector to L5/S1 (cm).

$\mathrm{D}=$ Distance horizontal force produced abdominal contractions of the diaphragm muscle $(\mathrm{cm})$.

$\theta_{\mathrm{H}}=$ The angle of inclination relative to the horizontal body $\left(^{\circ}\right)$.

$\theta_{\mathrm{T}}=$ The angle of inclination relative to the horizontal body $\left(^{\circ}\right)$.

$\theta_{\mathrm{A}} \quad=$ The angle between the pressure force relative to horizontal $\left({ }^{\circ}\right)$.

\section{Biomechanics}

In the design of the working methods need to be considered functions and muscle-skeletal system called biomechanics is the application of engineering mechanics to the analysis of human muscular-skeletal system. Biomechanics will provide the foundation for addressing the problem of human posture and movement in his place and space. Basic considerations in biomechanics are predicting an increase in the risk of the material removal process as a function of the following factors:

a. Weight load being transported.

b. Distance burden of worker's body (front or side).

c. Inclination angles formed at the time of appointment. The cumulative risk of injury increases with the distance the load to the body, this is because:

a. The greater burden detained by spine and back muscles so that the greater over exertion.

b. The power of appointment of the load will be reduced and the burden will be difficult to control.

c. The position of the body out of balance.

d. Position body bent.

E. Benefit Cost Ratio $(\mathrm{B} / \mathrm{C})$

a. Cost benefit analysis is analysis used to evaluate projects as a practical way to assess the benefit of a project. In this activity required a long and extensive review to see and analyze all the effects of the benefits and costs involved. In other words, the necessary analysis and evaluation of the various perspectives that are relevant to the charges/costs and benefits are donated.

b. The basis of the feasibility analysis of B / C is the ratio between the benefits given to the cost of keeping it. Benefit cost ratio is done by quantifying the benefits of a project if necessary in the form of units of currency. But in fact in some cases we are difficulties in menilaikan a benefit in units of currency. This can be done because the most important are the benefits and costs to be analyzed is equivalent means must be viewed from the same perspective. How frequently and easily used to determine this point is to first identify who receives the benefits and who pays the costs. Mathematically (Grant et al, 1990) cost-benefit analysis is formulated in equation 13

c. Cost benefit analysis is used to evaluate projects analysis as a practical way to assess the benefit of a project. In this activity required a long and extensive review to see and analyze all the effects of the benefits and costs involved. In other words, the necessary analysis and evaluation of the various perspectives that are relevant to the charges / costs and benefits are donated.

d. The basis of the feasibility analysis of $B / C$ is the ratio between the benefits given to the cost of keeping it. Benefit cost ratio is done by quantifying the benefits of a project if necessary in the form of units of currency. But in fact in some cases we are have difficulties in assessing a benefit in units of currency. This can be done because the most important are the benefits and costs to be analyzed is equivalent means must be viewed from the same perspective. How frequently and easily used to determine this point is to first identify who receives the benefits and who pays the costs. Mathematically (Grant, 1990) costbenefit analysis is formulated in equation 13.

e. $B / C=\frac{\text { benefit equivalent }}{\cos t \text { eqivalent }}$

Where :

Ratio $B / C \geq 1$, is said to be economically viable alternative

Ratio $\mathrm{B} / \mathrm{C}<1$, the alternative is not feasible (cost minimization)

f. A variety of benefits that can arise from a project does not everything can be quantified especially in currency values. The principle which must be held within a cost benefit analysis, not merely measure the values of the benefits and costs in currency values, but more important is to convert the values of the benefits and costs to the measures that have been understood by the those involved both as sponsors and users of the project. In cases where size is very difficult to obtain quantitative, qualitative descriptions sometimes been considered enough. Most important in this is to see the extent to which the benefits and costs can be quantified.

g. In this analysis theoretical benefit cost ratio is used to analyze the level of usefulness of alternative repair method proposed MMH work. This usefulness can be measured from the reduction of the costs incurred in handling accidents. These costs may include the cost of direct damages and indirect losses costs. The cost of direct losses such as the costs ministration, treatment, care, wages for not being able to work, disability compensation, the cost of repair of equipment / facilities damaged due to accidents and material damage costs. As for indirect loss costs include the costs of time lost from work, the cost of cessation of work process because a commotion in the workplace (to help workers affected by the accident), and if the old worker is injured cannot work anymore, there will be an additional cost to recruit new workers (cost of training, the training, the cost of adaptation), and so on. 


\section{RESEARCH METHODS}

a. Observations MMH work situation

b. Discomfort survey deployment job to know the place and the level of perceived grievances of workers.

c. Retrieval of data for the calculation of Chaffin model.

d. Propose an alternative system MMH work.

e. Calculate the benefits of each proposed alternative.

\section{EXAMPLE Of THE Benefit Cost RATIO (B/C)}

Method B / C measures the feasibility of an alternative based on the ratio between a given level of benefits and costs. If the value of $\mathrm{B} / \mathrm{C} \geq 1$ is said to be economically viable alternative, and vice versa.(see in Table 3 )

\section{CONCLUSION}

That the $\mathrm{B} / \mathrm{C}$ methods can be used to evaluate the feasibility of MMH ergonomics by incorporating therein the risk factors.

\section{REFERENCES}

[1]. Ayoub, M. M. \& Mital, A. (1989). Manual Material Handling. Taylor \& Francis Inc. London-New York-Philadelphia.

[2]. Chaffin, D.B., Andres, R.O., Garg, A., 1984. Volitional postures during maximal push/ pull exertions in the sagittal plane. Hum. Factors 25 (5), 541-550

[3]. Chaffin, D.B., 1991. Occupational biomechanics, Wiley New York.

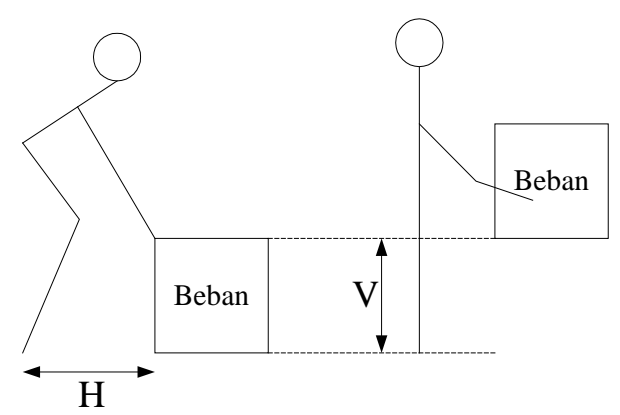

Figure 1. Variable horizontal (H) and vertical (V)

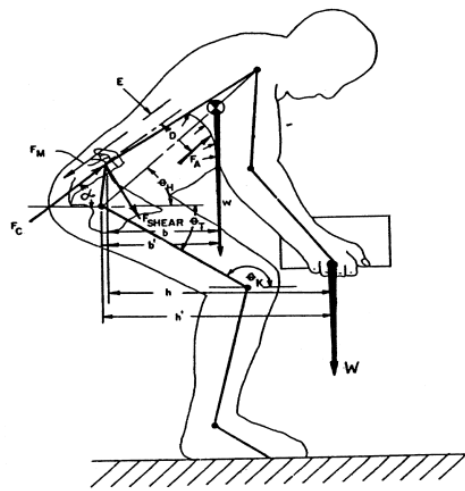

Figure 2. Lower back models are studied by Chaffin for biomechanical analysis (Chaffin, 1984)
[4]. Hendrick, H.W., 1996. Good Ergonomics is Good Economics Human Factors and Ergonomics Society, Santa Monica, CA.

[5]. Hendrick, H.W., 2003. Determining the cost-benefits of ergonomics projects and factors that lead to their success. Applied Ergonomics 34, 419-427.

[6]. Nurmianto, Eko (2004) Ergonomi : Konsep dasar dan aplikasinya. Guna Widya : Surabaya

[7]. Eugene L. Grant, W. Grant Ireson, Richard S. Leavenworth (1990) Principles of Engineering Economy, 8th Edition. John Wiley \& Sons.

[8]. Rivilis, I., Van Eerda, D., Cullena, K., Cole, D.C., Irvina, E., Tysonc, J., Mahood, Q., 2008. Effectiveness of participatory ergonomic interventions on health outcomes: a systematic review. Applied Ergonomics 39, 342-358.

[9]. Snook, S.H., 1978. The design of manual handling tasks Ergonomics 21, 963-985

[10]. Snook, S.H., Ciriello, V.M., 1991. The design of manual handling tasks: revised tables of maximum acceptable weights and forces. Ergonomics 34, 1197-1213.

[11]. Simpson, G.C., 1988. The economic justification for ergonomics. International Journal of Industrial Ergonomics 2, 157-163.

[12]. Tompa, E., Dolinschi, R., Laing, A., 2009. An economic evaluation of a participatory ergonomics process in an auto parts manufacturer. Journal of Safety Research 40, 41-47.

[13]. Zurada, J. (2012). Predicting Low Back Disorders Due to Manual Handling Tasks. In R. Sprague (Ed.), Proceedings of the 45th Hawaii international conference on system sciences, IEEE Computer Society Press.

[14]. Zurada, J., Karwowski, W., \& Marras, W.S. (2004) Classification of jobs with risk of low back disorders by applying data mining techniques. Occupational Ergonomics, 4(4), 291-305.

TABLE 1.

FREQUENCY MULTIPLIER FACTOR

\begin{tabular}{|c|c|c|c|c|c|c|}
\hline \multirow{2}{*}{$\begin{array}{l}\text { Frequency } \\
\text { force per } \\
\text { minute }\end{array}$} & \multicolumn{6}{|c|}{ Working duration } \\
\hline & $\begin{array}{c}\mathrm{V} \\
<75\end{array}$ & $\begin{array}{c}\mathrm{V} \\
\geq 75\end{array}$ & $\begin{array}{c}\mathrm{V} \\
<75 \\
\end{array}$ & $\begin{array}{c}\mathrm{V} \\
\geq 75 \\
\end{array}$ & $\begin{array}{c}\mathrm{V} \\
<75\end{array}$ & $\begin{array}{c}\mathrm{V} \\
\geq 75\end{array}$ \\
\hline 0,2 & 1,00 & 1,00 & 0,95 & 0,95 & 0,85 & 0,85 \\
\hline 0,5 & 0,97 & 0,97 & 0,92 & 0,92 & 0,81 & 0,81 \\
\hline 1 & 0,94 & 0,94 & 0,88 & 0,88 & 0,75 & 0,75 \\
\hline 2 & 0,91 & 0,91 & 0,84 & 0,84 & 0,65 & 0,65 \\
\hline 3 & 0,88 & 0,88 & 0,79 & 0,79 & 0,55 & 0,55 \\
\hline 4 & 0,84 & 0,84 & 0,72 & 0,72 & 0,45 & 0,45 \\
\hline 5 & 0,80 & 0,80 & 0,60 & 0,60 & 0,35 & 0,35 \\
\hline 6 & 0,75 & 0,75 & 0,50 & 0,50 & 0,27 & 0,27 \\
\hline 7 & 0,70 & 0,70 & 0,42 & 0,42 & 0,22 & 0,22 \\
\hline 8 & 0,60 & 0,60 & 0,35 & 0,35 & 0,18 & 0,18 \\
\hline 9 & 0,52 & 0,52 & 0,30 & 0,30 & 0,00 & 0,15 \\
\hline 10 & 0,45 & 0,45 & 0,26 & 0,26 & 0,00 & 0,13 \\
\hline 11 & 0,41 & 0,41 & 0,00 & 0,23 & 0,00 & 0,00 \\
\hline 12 & 0,37 & 0,37 & 0,00 & 0,21 & 0,00 & 0,00 \\
\hline 13 & 0,00 & 0,34 & 0,00 & 0,00 & 0,00 & 0,00 \\
\hline 14 & 0,00 & 0,31 & 0,00 & 0,00 & 0,00 & 0,00 \\
\hline 15 & 0,00 & 0,28 & 0,00 & 0,00 & 0,00 & 0,00 \\
\hline$>15$ & 0,00 & 0,00 & 0,00 & 0,00 & 0,00 & 0,00 \\
\hline
\end{tabular}


TABLE 2 .

COUPLING MULTIPLIER FACTOR

\begin{tabular}{ccc}
\hline \hline & \multicolumn{2}{c}{ Multiplier Factor } \\
$\begin{array}{c}\text { Coupling } \\
\text { quality }\end{array}$ & $\mathrm{V}<75 \mathrm{~cm}(30 \mathrm{in})$ & $\mathrm{V} \geq 75 \mathrm{~cm}(30 \mathrm{in})$ \\
\hline Good & 1,00 & 1,00 \\
Enough & 0,95 & 1,00 \\
Less & 0,90 & 0,90 \\
\hline \hline
\end{tabular}

TABLE 3.

IDENTIFICATION OF COSTS AND BENEFITS TO EACH ALTERNATIVE

\begin{tabular}{|c|c|c|}
\hline \multicolumn{3}{|c|}{ TO EACH ALTERNATIVE } \\
\hline & Cost & Benefit \\
\hline $\begin{array}{c}\text { Alternative } \\
1\end{array}$ & $\begin{array}{c}\text { Price of } \\
\text { table }\end{array}$ & $\begin{array}{l}\text { - Reduction in the cost of care } \\
\text { workers. } \\
\text { - Reduction of costs incurred due to } \\
\text { lost work time. }\end{array}$ \\
\hline $\begin{array}{c}\text { Alternative } \\
2\end{array}$ & $\begin{array}{l}\text { Wage / } \\
\text { salary } \\
\text { workers }\end{array}$ & $\begin{array}{l}\text { - Reduction in the cost of care } \\
\text { workers. } \\
\text { - Reduction of costs incurred due to } \\
\text { lost work time. }\end{array}$ \\
\hline $\begin{array}{c}\text { Alternative } \\
3\end{array}$ & - & $\begin{array}{l}\text { - Reduction in the cost of care } \\
\text { workers. } \\
\text { - Reduction of costs incurred due to } \\
\text { lost work time. }\end{array}$ \\
\hline
\end{tabular}

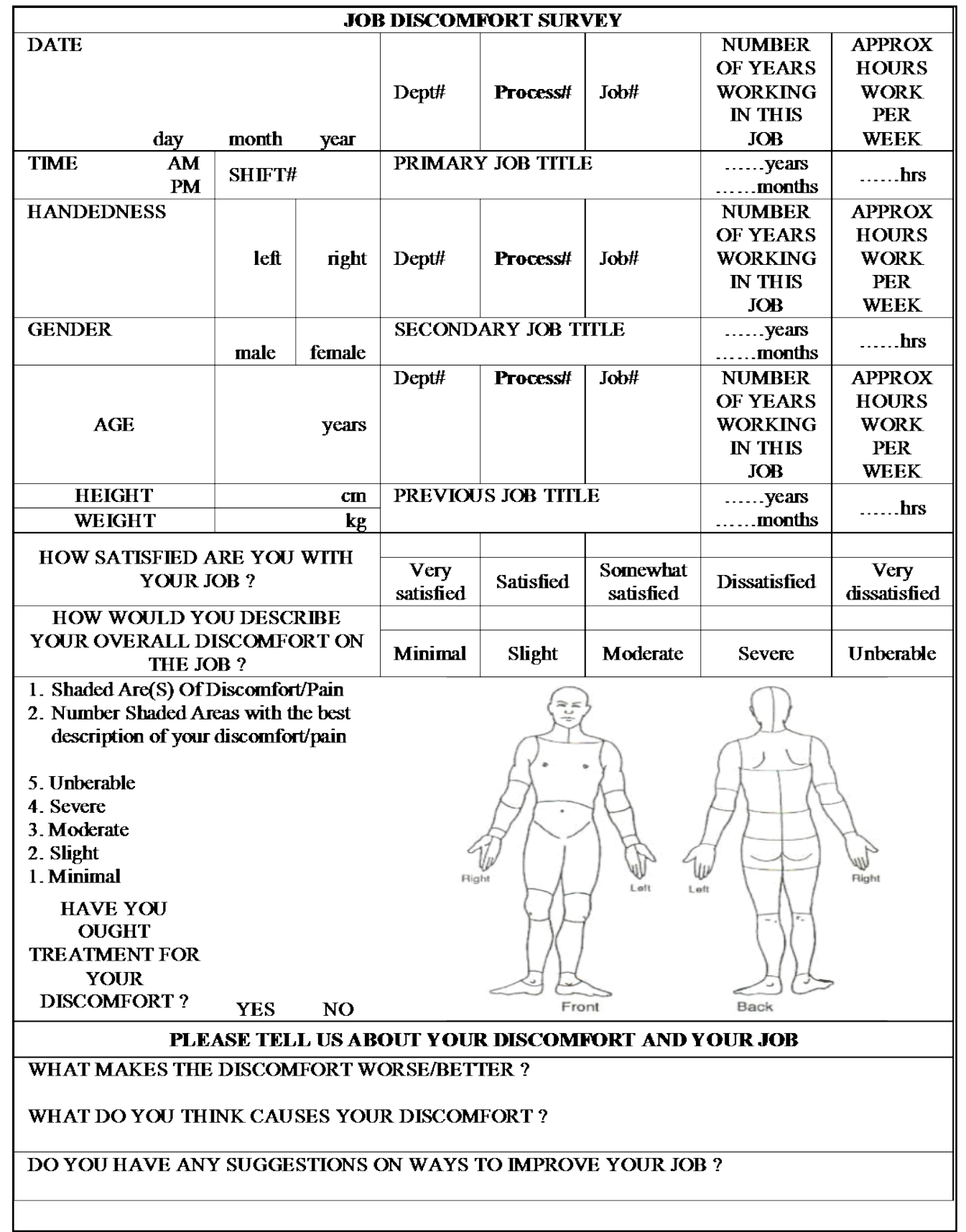

Figure 3. Job Discomfort Survey Form (Nurmianto, 2004) 